\title{
Effects of the COVID-19 pandemic on pediatric trauma in Southern California
}

\author{
Eric O. Yeates ${ }^{1} \cdot$ Areg Grigorian ${ }^{1,2} \cdot$ Morgan Schellenberg $^{2} \cdot$ Natthida Owattanapanich $^{2} \cdot$ Galinos Barmparas $^{3}$. \\ Daniel Margulies ${ }^{3} \cdot$ Catherine Juillard $^{4} \cdot$ Kent Garber $^{4} \cdot$ Henry Cryer $^{4} \cdot$ Areti Tillou $^{4} \cdot$ Sigrid Burruss $^{5}$. \\ Liz Penaloza-Villalobos ${ }^{5} \cdot$ Ann Lin $^{5} \cdot$ Ryan Arthur Figueras $^{5} \cdot$ Raul Coimbra $^{5,6} \cdot$ Megan Brenner $^{7} \cdot$ Todd Costantini $^{8}$. \\ Jarrett Santorelli ${ }^{8}$. Terry Curry ${ }^{8} \cdot$ Diane Wintz $^{9} \cdot$ Walter L. Biff $^{10} \cdot$ Kathryn B. Schaffer $^{10}$. Thomas K. Duncan $^{11}$. \\ Casey Barbaro ${ }^{11}$. Graal Diaz ${ }^{11}$. Arianne Johnson ${ }^{12}$. Justine Chinn ${ }^{1}$. Ariana Naaseh ${ }^{1}$. Amanda Leung ${ }^{1}$. \\ Christina Grabar ${ }^{1} \cdot$ Jeffry Nahmias ${ }^{1} \mathbb{0}$
}

Accepted: 20 November 2021 / Published online: 1 December 2021

(c) The Author(s) 2021

\begin{abstract}
Purpose The COVID-19 pandemic resulted in increased penetrating trauma and decreased length of stay (LOS) amongst the adult trauma population, findings important for resource allocation. Studies regarding the pediatric trauma population are sparse and mostly single-center. This multicenter study examined pediatric trauma patients, hypothesizing increased penetrating trauma and decreased LOS after the 3/19/2020 stay-at-home (SAH) orders.

Methods A multicenter retrospective analysis of trauma patients $\leq 17$ years old presenting to 11 centers in California was performed. Demographic data, injury characteristics, and outcomes were collected. Patients were divided into three groups based on injury date: 3/19/2019-6/30/2019 (CONTROL), 1/1/2020-3/18/2020 (PRE), 3/19/2020-6/30/2020 (POST). POST was compared to PRE and CONTROL in separate analyses.

Results 1677 patients were identified across all time periods (CONTROL: 631, PRE: 479, POST: 567). POST penetrating trauma rates were not significantly different compared to both PRE (11.3 vs. 9.0\%, $p=0.219)$ and CONTROL $(11.3$ vs. $8.2 \%$, $p=0.075)$, respectively. POST had a shorter mean LOS compared to PRE (2.4 vs. 3.3 days, $p=0.002)$ and CONTROL ( 2.4 vs. 3.4 days, $p=0.002$ ). POST was also not significantly different than either group regarding intensive care unit (ICU) LOS, ventilator days, and mortality (all $p>0.05$ ).

Conclusions This multicenter retrospective study demonstrated no difference in penetrating trauma rates among pediatric patients after SAH orders but did identify a shorter LOS.
\end{abstract}

Keywords Pediatric $\cdot$ Trauma $\cdot$ COVID-19 $\cdot$ Pandemic $\cdot$ Penetrating

\section{Introduction}

The COVID-19 pandemic resulted in stay-at-home (SAH) orders and other mandates designed to slow the spread of disease [1-3]. These restrictions also triggered business closures, economic losses, and psychological stressors that have significantly impacted society [4-11]. These changes have been particularly detrimental to children who have also been impacted by school closures and social isolation [12-16]. Therefore, injury patterns and outcomes within the pediatric

Jeffry Nahmias

jnahmias@hs.uci.edu

Extended author information available on the last page of the article trauma population had the potential to change during the pandemic.

Significant shifts within the adult trauma population during COVID-19 are now well described and include an increase in penetrating trauma and drug use, variations in trauma volume based on insurance status, and a shorter length of stay (LOS) [17-26]. However, studies dedicated to the pediatric trauma population are sparse and have been mostly single-center in design [27-34]. One of these studies demonstrated a similar increase in pediatric penetrating trauma, as has been seen with adult trauma, during the COVID-19 pandemic [27]. Another study reporting that child-involved shooting incidents increased in 2020 during the COVID-19 pandemic also supports the possibility 
that penetrating trauma rates are increasing in the pediatric population [35].

Therefore, we sought to explore the changes in mechanisms and outcomes among the pediatric trauma population during the COVID-19 pandemic in a multicenter study, as these could affect resource allocation in the future. We hypothesized an increase in penetrating trauma rates and a shorter LOS in the Southern California pediatric trauma population after the March 19, 2020 SAH orders [36].

\section{Methods}

A post hoc analysis of pediatric trauma patients presenting to 11 American College of Surgeons (ACS) Level I and II trauma centers in Southern California between $1 / 1 / 2020-6 / 30 / 2020$ and 3/19/2019-6/30/2019 was performed. These 11 centers span 7 counties in Southern California and comprise a mixture of academic and private hospitals that serve mostly urban areas. The study was approved by the Institutional Review Board (IRB) of University of California, Irvine and all participating centers and was deemed exempt from need for consent.

All patients $\leq 17$ years old who were either a trauma activation or trauma consult were included in this study. The primary outcome was the rate of penetrating trauma, categorized as either gunshot wounds, stab wounds, or other. The secondary outcome was LOS. Other outcomes were intensive care unit (ICU) admission, ICU LOS, ventilator days, operations performed (tracheostomy, laparotomy, craniectomy/craniotomy, and vascular/endovascular surgery), and mortality. Demographic data were collected which included sex (self-reported), age, race, insurance status (i.e., Medicaid, private, and uninsured), and body mass index (BMI). Other mechanisms of injury recorded included motor vehicle collisions (MVC), pedestrian struck, motorcycle collision (MCC), sports injuries, ground level falls (GLF), falls from height, and assaults. Injury severity score (ISS), serum alcohol positivity, and urine toxicology were also recorded. Vital signs and exam findings on arrival were also collected and included heart rate (HR), respiratory rate (RR), systolic blood pressure (SBP), and Glasgow Coma Scale (GCS) score. Discharge disposition was collected and included home, long-term acute care hospital (LTAC), and acute rehabilitation.

Patients were then divided into three groups based on the date of injury: a historical control from 3/19/2019-6/30/2019 (CONTROL), immediately before the SAH order from $1 / 1 / 2020-3 / 18 / 2020$ (PRE), and after the SAH order 3/19/2020-6/30/2020 (POST). Descriptive statistics were performed for all variables within each group, with categorical variables reported as percentages of their respective group and continuous variables as means with standard deviations. The POST group was compared to the PRE group and the CONTROL group in two separate analyses. This was done to account for both seasonal and annual variations that exist within the trauma population. Additionally, different subgroups including patients 12 years and older, younger than 12 years old, ISS greater than or equal to 10, and ISS less than 10 were created. LOS was compared between the three time periods for each subgroup. Chi-square tests were used to compare categorical variables and Mann-Whitney $U$ tests for continuous variables. Next, multivariable logistic regression utilizing time period, age, race, insurance status, and ISS was performed to identify independent risk factors for a LOS longer than 2 days. The adjusted risk of LOS longer than 2 days was reported as an odds ratio (OR) with a $95 \%$ confidence interval (CI). $p$ values $<0.05$ were considered statistically significant. All analyses were performed using IBM SPSS Statistics for Windows (Version 24, IBM Corp., Armonk, NY).

\section{Results}

A total of 1677 trauma patients were identified across the 3 time periods: 631 patients in the CONTROL group, 479 in the PRE group, and 567 in the POST group.

\section{PRE vs. POST demographics}

Compared to the PRE group, the POST group had a higher percentage of white $(42.0$ vs. $35.9 \%, p=0.045)$ and Black (9.3 vs. $5.8 \%, p=0.035)$ patients, but a lower percentage of Latino patients ( 41.1 vs. $50.3 \%, p=0.003$ ). The POST group also had significantly higher rate of Medicaid (46.9 vs. $31.5 \%, p<0.001$ ), but lower rate of private insurance ( 43.0 vs. $56.6 \%, p<0.001$ ). Otherwise, the two groups were similar regarding sex, age, race, insurance status, and BMI (all p > 0.05) (Table 1).

\section{CONTROL vs. POST demographics}

Compared to the CONTROL group, the POST group had a higher rate of Medicaid (46.9 vs. 34.2\%, $p<0.001$ ), but lower rates of private insurance ( 43.0 vs. $57.4 \%, p<0.001$ ) and no insurance ( 3.9 vs. $6.5 \%, p=0.043$ ). The POST group also had a higher mean BMI (21.3 vs. $\left.20.1 \mathrm{~kg} / \mathrm{m}^{2}, p=0.006\right)$. Otherwise, the two groups were similar regarding sex, age, and race (all $p>0.05$ ) (Table 1).

\section{PRE vs. POST injury characteristics, toxicology, and vital signs}

Compared to the PRE group, the POST group had a similar rate of penetrating trauma $(11.3$ vs. $9.0 \%, p=0.219)$ 
Table 1 Demographics of pediatric trauma patients compared by time period

\begin{tabular}{|c|c|c|c|c|c|}
\hline Characteristic & $\operatorname{POST}(n=567)$ & $\operatorname{PRE}(n=479)$ & $\begin{array}{l}\text { PRE vs POST } \\
p \text { value }\end{array}$ & CONTROL $(n=631)$ & $\begin{array}{l}\text { CONTROL vs POST } \\
p \text { value }\end{array}$ \\
\hline Male, $n(\%)$ & $366(64.6 \%)$ & $293(61.2 \%)$ & 0.259 & $419(66.4 \%)$ & 0.501 \\
\hline Age, years, mean \pm SD & $9.9 \pm 5.6$ & $10.0 \pm 5.6$ & 0.833 & $10.1 \pm 5.6$ & 0.685 \\
\hline \multicolumn{6}{|l|}{ Race, $n(\%)$} \\
\hline White & $238(42.0 \%)$ & $172(35.9 \%)$ & 0.045 & $250(39.6 \%)$ & 0.407 \\
\hline Latino & $233(41.1 \%)$ & $241(50.3 \%)$ & 0.003 & $254(40.3 \%)$ & 0.768 \\
\hline Black & $53(9.3 \%)$ & $28(5.8 \%)$ & 0.035 & $54(8.6 \%)$ & 0.632 \\
\hline Asian & $15(2.6 \%)$ & $15(3.1 \%)$ & 0.639 & $16(2.5 \%)$ & 0.905 \\
\hline \multicolumn{6}{|l|}{ Insurance status, $n(\%)$} \\
\hline Medicaid & $266(46.9 \%)$ & $151(31.5 \%)$ & $<0.001^{+}$ & $216(34.2 \%)$ & $<0.001^{+}$ \\
\hline Private & $244(43.0 \%)$ & $271(56.6 \%)$ & $<0.001^{+}$ & $362(57.4 \%)$ & $<0.001^{+}$ \\
\hline Uninsured & $22(3.9 \%)$ & $30(6.3 \%)$ & 0.077 & $41(6.5 \%)$ & 0.043 \\
\hline $\mathrm{BMI}, \mathrm{kg} / \mathrm{m}^{2}$, mean $\pm \mathrm{SD}$ & $21.3 \pm 6.3$ & $20.8 \pm 5.9$ & 0.220 & $20.1 \pm 5.5$ & 0.006 \\
\hline
\end{tabular}

Bolded values are significantly different

SD standard deviation, BMI body mass index, CONTROL 3/19/19-6/30/19, PRE 1/1/20-3/18/20, POST 3/19/20-6/30/20

${ }^{+}$Significantly different in both comparisons

including both gunshot and stab wounds individually (both $p>0.05$ ), but a lower rate of MVC (21.2 vs. $27.3 \%$, $p=0.020)$. Otherwise, the groups were similar in terms of mechanism of injury, alcohol/drug positivity, ISS, and vital signs on arrival (all $p>0.05$ ) (Table 2).

\section{CONTROL vs. POST injury characteristics, toxicology, and vital signs}

Compared to the CONTROL group, the POST group had a similar penetrating trauma rate $(11.3$ vs. $8.2 \%, p=0.075)$ including both gunshot and stab wounds individually (both $p>0.05)$. However, the POST group had lower rates of pedestrians struck (6.7 vs. 10.3\%, $p=0.027$ ) and MCC (3.9 vs. $7.6 \%, p=0.006)$. The POST group had a higher mean SBP (122.2 vs. $120.4 \mathrm{mmHg}, p=0.045)$ and HR (108.1 vs. 105.1 beats per minute, $p=0.010$ ) on arrival. Otherwise, the two groups were similar with regards to mechanism of injury, alcohol/drug positivity, and vital signs on arrival (all $p>0.05$ ) (Table 2).

\section{PRE vs. POST Outcomes}

Compared to the PRE group, the POST group had a shorter mean LOS (2.4 vs. 3.3 days, $p=0.002$ ). The POST group also had higher rates of discharge to home (80.6 vs. $75.6 \%$, $p=0.049)$, but lower rates of discharge to acute rehabilitation ( 1.8 vs. $3.8 \%, p=0.047)$. Otherwise, the two groups were similar in terms of ICU admission, ICU LOS, ventilator days, operations, discharge disposition, and mortality (all $p>0.05$ ) (Table 3).

\section{CONTROL vs. POST Outcomes}

Compared to the CONTROL group, the POST group had a shorter mean LOS (2.4 vs. 3.4 days, $p=0.002)$ and a lower rate of laparotomy (2.0 vs. $2.8 \%, p=0.002)$. Otherwise, the two groups were similar in terms of ICU admission, ICU LOS, ventilator days, discharge disposition, and mortality (all $p>0.05)$ (Table 3).

\section{Mechanisms of injury of pediatric trauma patients by time period}

In the POST group, there were 503 patients who sustained blunt and 64 who sustained penetrating injuries. In the PRE group, 436 sustained blunt and 43 sustained penetrating injuries. In the CONTROL group, 579 patients sustained blunt injuries and 52 sustained penetrating injuries (Fig. 1).

\section{Length of stay for different pediatric trauma subgroups compared by time period}

Among patients 12 years and older, mean LOS was significantly shorter in the POST group compared to both the PRE and CONTROL groups, respectively (2.5 vs 3.5 days, $p=0.026$ ) (2.5 vs 3.5 days, $p=0.032$ ). In patients younger than 12 years, LOS was similarly shorter in the POST group (2.2 vs 3.1 days, $p=0.022$ ) (2.2 vs 3.2 days, $p=0.003$ ). Among patients with an ISS greater than or equal to 10 , mean LOS was significantly shorter in the POST group compared to both the PRE and CONTROL groups, respectively (4.5 vs 7.8 days, $p=0.004$ ) (4.5 vs 8.9 days, $p<0.001)$. In patients with an ISS less than 10 , LOS of the POST group 
Table 2 Injury characteristics, toxicology, and vital signs of pediatric trauma patients compared by time period

\begin{tabular}{|c|c|c|c|c|c|}
\hline \multirow[t]{2}{*}{ Characteristic } & \multirow[t]{2}{*}{$\operatorname{POST}(n=567)$} & \multirow[t]{2}{*}{$\operatorname{PRE}(n=479)$} & PRE vs POST & \multirow[t]{2}{*}{ CONTROL $(n=631)$} & \multirow{2}{*}{$\begin{array}{l}\text { CONTROL vs } \\
\text { POST } \\
p \text { value }\end{array}$} \\
\hline & & & $p$ value & & \\
\hline \multicolumn{6}{|l|}{ Mechanism of injury, $n(\%)$} \\
\hline Blunt & $503(88.7 \%)$ & $436(91.0 \%)$ & 0.219 & $579(91.8 \%)$ & 0.075 \\
\hline Ground level fall & $87(15.3 \%)$ & $64(13.4 \%)$ & 0.363 & $91(14.4 \%)$ & 0.654 \\
\hline Fall from height & $76(13.4 \%)$ & $49(10.2 \%)$ & 0.115 & $82(13.0 \%)$ & 0.835 \\
\hline Pedestrian struck & $38(6.7 \%)$ & $43(9.0 \%)$ & 0.170 & $65(10.3 \%)$ & 0.027 \\
\hline Motorcycle collision & $22(3.9 \%)$ & $17(3.5 \%)$ & 0.778 & $48(7.6 \%)$ & 0.006 \\
\hline Motor vehicle collision & $120(21.2 \%)$ & $131(27.3 \%)$ & 0.020 & $140(22.2 \%)$ & 0.668 \\
\hline Assault & $30(5.3 \%)$ & $21(4.4 \%)$ & 0.497 & $48(7.6 \%)$ & 0.105 \\
\hline Sports injury & $62(10.9 \%)$ & $44(9.2 \%)$ & 0.350 & $61(9.7 \%)$ & 0.470 \\
\hline Penetrating & $64(11.3 \%)$ & $43(9.0 \%)$ & 0.219 & $52(8.2 \%)$ & 0.075 \\
\hline Gunshot & $25(4.4 \%)$ & $22(4.6 \%)$ & 0.886 & $27(4.3 \%)$ & 0.912 \\
\hline Stab wound & $13(2.3 \%)$ & $8(1.7 \%)$ & 0.474 & $13(2.1 \%)$ & 0.783 \\
\hline Alcohol positive, $n(\%)$ & $53(9.3 \%)$ & $44(9.2 \%)$ & 0.928 & $58(9.2 \%)$ & 0.926 \\
\hline Urine toxicology positive, $n(\%)$ & $82(14.4 \%)$ & $77(16.1 \%)$ & 0.469 & $72(11.4 \%)$ & 0.115 \\
\hline ISS, mean \pm SD & $7.3 \pm 7.5$ & $7.4 \pm 8.0$ & 0.920 & $7.8 \pm 9.5$ & 0.594 \\
\hline \multicolumn{6}{|l|}{ Vitals on admission, mean \pm SD } \\
\hline Systolic blood pressure, $\mathrm{mmHg}$ & $122.2 \pm 18.1$ & $121.5 \pm 18.2$ & 0.556 & $120.4 \pm 17.9$ & 0.045 \\
\hline Respiratory rate, breaths per minute & $21.1 \pm 5.8$ & $21.7 \pm 6.5$ & 0.208 & $21.1 \pm 7.4$ & 0.354 \\
\hline Heart rate, beats per minute & $108.1 \pm 25.4$ & $105.8 \pm 25.5$ & 0.100 & $105.1 \pm 27.1$ & 0.010 \\
\hline GCS score & $14.1 \pm 2.7$ & $14.1 \pm 2.7$ & 0.327 & $14.1 \pm 2.8$ & 0.704 \\
\hline
\end{tabular}

Bolded values are significantly different

ISS injury severity score, SD standard deviation, GCS Glasgow coma scale, CONTROL 3/19/19-6/30/19, PRE 1/1/20-3/18/20, POST 3/19/20$6 / 30 / 20$

was not significantly different than that of the other two time periods $(p>0.05)$ (Table 4$)$.

\section{Multivariable logistic regression analysis for risk of LOS longer than 2 days in pediatric trauma patients}

On multivariable logistic regression analysis, an ISS greater than 15 was an independent associated risk factor for LOS longer than 2 days $(\mathrm{OR}=4.99$, CI 3.42-7.29, $p<0.001)$. Presenting during the POST period was associated with a decreased risk of having a LOS longer than 2 days $(\mathrm{OR}=0.66, \mathrm{CI} 0.54-0.82, p=<0.001)$ (Table 5).

\section{Discussion}

There are few studies detailing the effects the COVID-19 pandemic has had on pediatric trauma mechanisms and outcomes. This retrospective multicenter study across Southern California found no difference in penetrating trauma rates after SAH orders including analyses on gunshot and stab wounds specifically. However, there was a shorter mean LOS in the POST cohort compared to both the PRE and CONTROL groups. There were no differences between cohorts in terms of other parameters such as drug and alcohol positivity and insurance status.

A rise in community violence during COVID-19 has resulted in a parallel increase in penetrating trauma rates among adults, but has not definitively affected the pediatric trauma population [37-40]. This current multicenter study found a slightly higher although statistically similar penetrating trauma rate among pediatric patients before and after SAH orders. Though some of our other findings, including a decrease in MVC, MCC, and pedestrians struck, are similar to that of prior studies, our findings regarding penetrating trauma oppose those reported by Sherman et al. who found an increase in penetrating trauma among pediatric patients during COVID-19 [27]. However, Sherman et al.'s study had a number of limitations including the inclusion of 18and 19-year-old patients and the classification of animal bites (which comprised $42 \%$ of penetrating trauma in the study) as penetrating trauma which has different trauma and societal implications. Moreover, only a single comparison was made to the mean of the prior 4 years, which does not take into account there may have been a pre-existing annual 
Table 3 Outcomes of pediatric trauma patients compared by time period

\begin{tabular}{|c|c|c|c|c|c|}
\hline \multirow[t]{2}{*}{ Outcome } & \multirow[t]{2}{*}{ POST $(n=567)$} & \multirow[t]{2}{*}{$\operatorname{PRE}(n=479)$} & PRE vs POST & \multirow[t]{2}{*}{ CONTROL $(n=631)$} & \multirow{2}{*}{$\begin{array}{l}\text { CONTROL vs } \\
\text { POST } \\
p \text { value }\end{array}$} \\
\hline & & & $p$ value & & \\
\hline LOS, days, mean \pm SD & $2.4 \pm 2.9$ & $3.3 \pm 5.8$ & $\mathbf{0 . 0 0 2}^{+}$ & $3.4 \pm 6.2$ & $\mathbf{0 . 0 0 2}^{+}$ \\
\hline ICU admission, $n(\%)$ & $120(21.2 \%)$ & $122(25.5 \%)$ & 0.010 & $148(23.5 \%)$ & 0.342 \\
\hline ICU LOS, days, mean \pm SD & $0.6 \pm 1.7$ & $1.1 \pm 4.2$ & 0.103 & $1.0 \pm 3.3$ & 0.226 \\
\hline Mechanical ventilation, $n(\%)$ & $42(7.4 \%)$ & $41(8.6 \%)$ & 0.492 & $47(7.4 \%)$ & 0.978 \\
\hline Ventilator, days, mean $\pm \mathrm{SD}$ & $0.3 \pm 1.2$ & $0.6 \pm 3.1$ & 0.451 & $0.5 \pm 2.4$ & 0.872 \\
\hline \multicolumn{6}{|l|}{ Operations, $n(\%)$} \\
\hline Tracheostomy & $3(0.5 \%)$ & $4(0.8 \%)$ & 0.545 & $4(0.6 \%)$ & 0.812 \\
\hline Laparotomy & $6(1.1 \%)$ & $11(2.3 \%)$ & 0.115 & $21(3.3 \%)$ & 0.008 \\
\hline Craniectomy/craniotomy & $10(1.8 \%)$ & $14(2.9 \%)$ & 0.212 & $16(2.5 \%)$ & 0.360 \\
\hline Vascular/endovascular & $2(0.4 \%)$ & $3(0.6 \%)$ & 0.523 & $2(0.3 \%)$ & 0.915 \\
\hline \multicolumn{6}{|l|}{ Discharge disposition, $n(\%)$} \\
\hline Home & $457(80.6 \%)$ & $362(75.6 \%)$ & 0.049 & $507(80.3 \%)$ & 0.903 \\
\hline Long-term acute care hospital & $5(0.9 \%)$ & $4(0.8 \%)$ & 0.935 & $6(1.0 \%)$ & 0.900 \\
\hline Acute rehabilitation & $10(1.8 \%)$ & $18(3.8 \%)$ & 0.047 & $18(2.9 \%)$ & 0.213 \\
\hline Mortality, $n(\%)$ & $11(1.9 \%)$ & $11(2.3 \%)$ & 0.689 & $19(3.0 \%)$ & 0.236 \\
\hline
\end{tabular}

Bolded values are significantly different

LOS length of stay, ICU intensive care unit, SD standard deviation, CONTROL 3/19/19-6/30/19, PRE 1/1/20-3/18/20, POST 3/19/20-6/30/20

${ }^{+}$Significantly different in both comparisons

Fig. 1 Mechanism of injury of pediatric trauma patients by time period. Bar graph with time periods, separated by blunt and penetrating mechanism of injury, displayed on the $x$-axis and the number of patients displayed on the $y$-axis

\section{Mechanism of Injury of Pediatric Trauma Patients by Time Period}

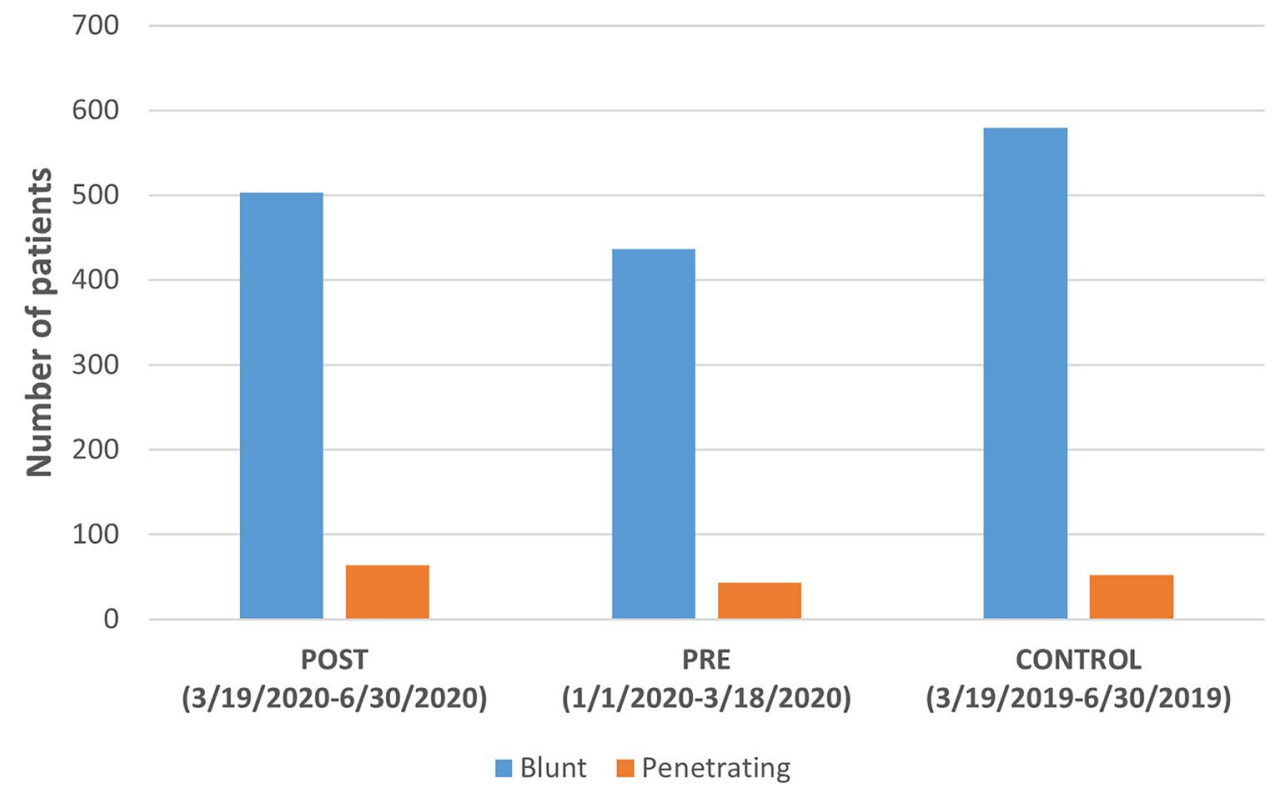

trend for increased penetrating trauma prior to the pandemic. In contrast, our study compares the COVID-19 data to the year prior, as well as the time frame immediately preceding the pandemic to account for this potential confounder.
Furthermore, findings of this multicenter study suggest that the pediatric trauma population was affected differently than the adult population by COVID-19 and SAH orders. This could be due to different pandemic-related stressors and 
Table 4 Length of stay for different pediatric trauma subgroups compared by time period

\begin{tabular}{lllllr}
\hline Subgroup & POST & PRE & \multicolumn{2}{l}{ PRE vs POST } & \multicolumn{2}{l}{\begin{tabular}{l} 
CONTROL \\
vs POST \\
\cline { 4 - 5 }
\end{tabular}} \\
& & & $p$ value & CONTROL & $p$ value \\
\hline Age $\geq 12$ years, days, mean \pm SD & $2.5 \pm 3.2$ & $3.5 \pm 5.9$ & $\mathbf{0 . 0 2 6}$ & $3.5 \pm 7.3$ & $\mathbf{0 . 0 3 2}$ \\
Age $<12$ years, days, mean \pm SD & $2.2 \pm 2.6$ & $3.1 \pm 5.8$ & $\mathbf{0 . 0 2 2}$ & $3.2 \pm 4.9$ & $\mathbf{0 . 0 0 3}$ \\
ISS $\geq 10$, days, mean \pm SD & $4.5 \pm 4.7$ & $7.8 \pm 10.3$ & $\mathbf{0 . 0 0 4}$ & $8.9 \pm 12.6$ & $<\mathbf{0 . 0 0 1}$ \\
ISS $<10$, days, mean \pm SD & $1.8 \pm 2.0$ & $2.0 \pm 2.1$ & 0.141 & $2.1 \pm 2.1$ & 0.089 \\
\hline
\end{tabular}

Bolded values are significantly different

ISS injury severity score, SD standard deviation, CONTROL 3/19/19-6/30/19, PRE 1/1/20-3/18/20, POST 3/19/20-6/30/20

${ }^{+}$Significantly different in both comparisons
Table 5 Multivariable logistic regression analysis for risk of length of stay (LOS) longer than 2 days in pediatric trauma patients

\begin{tabular}{lllr}
\hline Risk factor & OR & CI & $p$ value \\
\hline POST & 0.66 & $0.54-0.82$ & $<0.001$ \\
Age $\geq 12$ years & 0.87 & $0.71-1.10$ & 0.165 \\
Not white & 1.04 & $0.85-1.28$ & 0.707 \\
Not private insurance & 1.13 & $0.92-1.38$ & 0.246 \\
ISS $>15$ & 4.99 & $3.42-7.29$ & $<0.001$ \\
\hline
\end{tabular}

OR odds ratio, CI confidence interval, POST 3/19/20-6/30/20, ISS injury severity score

children being less affected by the violence that has risen in the community. These findings could be useful to pediatric trauma centers when planning for future pandemics, as they could improve resource allocation.

Predicting LOS in pediatric trauma patients is important for resource management, especially during a pandemic [41]. This study identified a 1 day shorter mean LOS during the COVID-19 pandemic, compared to both the time period immediately prior and a historical control. Furthermore, we were also able to show that presenting during the COVID-19 pandemic was associated with a decreased risk of having a hospital stay longer than 2 days, even after controlling for other risk factors of prolonged length of stay. These findings are similar to that of two prior studies identifying a decreased LOS during COVID, though one included only adults and the other included both adult and pediatric trauma patients $[7,24]$. To our knowledge, this study is the first to confirm these findings solely in a pediatric trauma population. The shorter LOS could be due to providers discharging patients earlier to conserve resources during a pandemic [42, 43]. These findings could also potentially indicate that LOS during non-pandemic times is unnecessarily long, though further prospective studies collecting readmission data are needed to confirm this.

There are a number of limitations to this study. First, this was a multicenter study that utilized multiple trauma registries and data collectors, which could have resulted in misclassification and missing variables. Second, this study does not include every trauma center in the region, making the subset of pediatric patients in this study not fully representative of the entire trauma population in Southern California. Additionally, the centers included in this study were not children's hospitals. Third, as this was a post hoc analysis with no prior power analysis, our lack of statistical significance could be due to a lack of power, although the population size was larger than the previous study which found a significant difference in penetrating trauma, but notably included animal bites. Next, we did not collect variables that would allow us to track changes in non-accidental trauma, which significantly increased in other studies, limiting us from fully exploring all the effects of COVID-19 on the pediatric trauma population [29, 33]. Finally, COVID19-related restrictions persisted for many months following our study period, suggesting this manuscript data may not fully represent all potential changes surrounding the COVID-19 pandemic.

\section{Conclusion}

This multicenter retrospective study in Southern California demonstrated similar penetrating trauma rates among pediatric trauma patients after SAH orders. However, the mean LOS was 1 day shorter compared to both the PRE and CONTROL cohorts. These findings may help trauma providers anticipate needs and allocate resources during future pandemics. In addition, future studies should be performed to evaluate if pediatric trauma LOS can be safely decreased during non-pandemic patient care.

Author contributions All authors contributed to the study conception and design. Material preparation, data collection and analysis were performed by EOY, AG, NO, GB, KG, LP-V, AL, RAF, TC, KBS, GD, AJ, JC, AN, AL, and CG. The first draft of the manuscript was 
written by EOY and all authors commented on previous versions of the manuscript. All authors read and approved the final manuscript.

Funding The authors did not receive support from any organization for the submitted work.

\section{Declarations}

Conflict of interest The authors have no relevant financial or non-financial interests to disclose.

Compliance with ethical standards This study was approved by the Institutional Review Board (IRB) of University of California, Irvine and all participating centers and was deemed exempt from need for consent.

Open Access This article is licensed under a Creative Commons Attribution 4.0 International License, which permits use, sharing, adaptation, distribution and reproduction in any medium or format, as long as you give appropriate credit to the original author(s) and the source, provide a link to the Creative Commons licence, and indicate if changes were made. The images or other third party material in this article are included in the article's Creative Commons licence, unless indicated otherwise in a credit line to the material. If material is not included in the article's Creative Commons licence and your intended use is not permitted by statutory regulation or exceeds the permitted use, you will need to obtain permission directly from the copyright holder. To view a copy of this licence, visit http://creativecommons.org/licenses/by/4.0/.

\section{References}

1. Zhu N, Zhang D, Wang W, Li X, Yang B, Song J et al (2019) A novel coronavirus from patients with pneumonia in China. N Engl J Med 382(8):727-733. https://doi.org/10.1056/NEJMoa2001017

2. Castillo RC, Staguhn ED, Weston-Farber E (2020) The effect of state-level stay-at-home orders on COVID-19 infection rates. Am J Infect Control 48(8):958-960. https://doi.org/10.1016/j.ajic. 2020.05.017

3. Borjas GJ (2020) Business closures, stay-at-home restrictions, and COVID-19 testing outcomes in New York City. Prev Chronic Dis 17:E109. https://doi.org/10.5888/pcd17.200264

4. Jacobsen GD, Jacobsen KH (2020) Statewide COVID-19 stay-athome orders and population mobility in the United States. World Med Health Policy. https://doi.org/10.1002/wmh3.350 (Epub 2020 July 29)

5. Gostin LO, Wiley LF (2020) Governmental public health powers during the COVID-19 pandemic: stay-at-home orders, business closures, and travel restrictions. JAMA 323(21):2137-2138. https://doi.org/10.1001/jama.2020.5460

6. Nicola M, Alsafi Z, Sohrabi C, Kerwan A, Al-Jabir A, Iosifidis C et al (2020) The socio-economic implications of the coronavirus pandemic (COVID-19): A review. Int J Surg 78:185-193. https:// doi.org/10.1016/j.ijsu.2020.04.018

7. Xiong J, Lipsitz O, Nasri F, Lui LMW, Gill H, Phan L et al (2020) Impact of COVID-19 pandemic on mental health in the general population: a systematic review. J Affect Disord 277:55-64. https://doi.org/10.1016/j.jad.2020.08.001

8. Rajkumar RP (2020) COVID-19 and mental health: a review of the existing literature. Asian J Psychiatr 52:102066. https://doi. org/10.1016/j.ajp.2020.102066
9. Wu T, Jia X, Shi H, Niu J, Yin X, Xie J, Wang X (2021) Prevalence of mental health problems during the COVID-19 pandemic: a systematic review and meta-analysis. J Affect Disord 281:91-98. https://doi.org/10.1016/j.jad.2020.11.117

10. Gloster AT, Lamnisos D, Lubenko J, Presti G, Squatrito V, Constantinou $\mathrm{M}$ et al (2020) Impact of COVID-19 pandemic on mental health: an international study. PLoS ONE 15(12):e0244809. https://doi.org/10.1371/journal.pone.0244809

11. Serafini G, Parmigiani B, Amerio A, Aguglia A, Sher L, Amore M (2020) The psychological impact of COVID-19 on the mental health in the general population. QJM 113(8):531-537. https:// doi.org/10.1093/qjmed/hcaa201

12. Nearchou F, Flinn C, Niland R, Subramaniam SS, Hennessy E (2020) Exploring the impact of COVID-19 on mental health outcomes in children and adolescents: a systematic review. Int J Environ Res Public Health 17(22):8479. https://doi.org/10.3390/ ijerph17228479

13. Zhu S, Zhuang Y, Ip P (2021) Impacts on children and adolescents' lifestyle, social support and their association with negative impacts of the COVID-19 pandemic. Int J Environ Res Public Health 18(9):4780. https://doi.org/10.3390/ijerph18094780

14. Tso WWY, Wong RS, Tung KTS, Rao N, Fu KW, Yam JCS et al (2020) Vulnerability and resilience in children during the COVID19 pandemic. Eur Child Adolesc Psychiatry 17:1-16. https://doi. org/10.1007/s00787-020-01680-8

15. Marques de Miranda D, da Silva AB, Sena Oliveira AC, SimoesE-Silva AC (2020) How is COVID-19 pandemic impacting mental health of children and adolescents? Int J Disaster Risk Reduct 51:101845. https://doi.org/10.1016/j.ijdrr.2020.101845

16. Varma P, Junge M, Meaklim H, Jackson ML (2020) Younger people are more vulnerable to stress, anxiety and depression during COVID-19 pandemic: a global cross-sectional survey. Prog Neuropsychopharmacol Biol Psychiatry 109:110236. https://doi. org/10.1016/j.pnpbp.2020.110236

17. Yeates EO, Grigorian A, Barrios C, Schellenberg M, Owattanapanich N, Barmparas G et al (2021) Changes in traumatic mechanisms of injury in Southern California related to COVID-19: penetrating trauma as a second pandemic. J Trauma Acute Care Surg 90(4):714-721. https://doi.org/10.1097/TA.0000000000003068

18. Ghafil C, Matsushima K, Ding L, Henry R, Inaba K (2021) Trends in trauma admissions during the COVID-19 pandemic in Los Angeles County, California. JAMA Netw Open 4(2):e211320. https://doi.org/10.1001/jamanetworkopen.2021.1320

19. Berg GM, Wyse RJ, Morse JL, Chipko J, Garland JM, Slivinski A et al (2021) Decreased adult trauma admission volumes and changing injury patterns during the COVID-19 pandemic at 85 trauma centers in a multistate healthcare system. Trauma Surg Acute Care Open 6(1):e000642. https://doi.org/10.1136/ tsaco-2020-000642

20. Chodos M, Sarani B, Sparks A, Bruns B, Gupta S, Michetti CP et al (2021) Impact of COVID-19 pandemic on injury prevalence and pattern in the Washington, DC Metropolitan Region: a multicenter study by the American College of Surgeons Committee on Trauma, Washington, DC. Trauma Surg Acute Care Open 6:e00659. https://doi.org/10.1136/tsaco-2020-000659

21. Sherman WF, Khadra HS, Kale NN, Wu VJ, Gladden PB, Lee OC (2021) How did the number and type of injuries in patients presenting to a regional level I trauma center change during the COVID-19 pandemic with a stay-at-home order? Clin Orthop Relat Res 479(2):266-275. https://doi.org/10.1097/CORR.00000 00000001484

22. Olding J, Zisman S, Olding C, Fan K (2021) Penetrating trauma during a global pandemic: changing patterns in interpersonal violence, self-harm and domestic violence in the Covid-19 outbreak. 
Surgeon 19(1):e9-e13. https://doi.org/10.1016/j.surge.2020.07. 004

23. Rhodes HX, Petersen K, Biswas S (2020) Trauma trends during the initial peak of the COVID-19 pandemic in the midst of lockdown: experiences from a rural trauma center. Cureus 12(8):e9811. https://doi.org/10.7759/cureus.9811

24. Leichtle SW, Rodas EB, Procter L, Bennett J, Schrader R, Aboutanos MB (2020) The influence of a statewide "Stay-at-Home" order on trauma volume and patterns at a level 1 trauma center in the United States. Injury 51(11):2437-2441. https://doi.org/10. 1016/j.injury.2020.08.014

25. Young KN, Yeates EO, Grigorian A, Schellenberg M, Owattanapanich N, Barmparas G et al (2021) Drug and alcohol positivity of trauma patients related to COVID-19 stay-at-home orders. Am J Drug Alcohol Abuse 4:1-7. https://doi.org/10.1080/00952990. 2021.1904967

26. Yeates EO, Juillard C, Grigorian A, Schellenberg M, Owattanapanich N, Barmparas G et al (2021) The coronavirus disease 2019 (COVID-19) stay-at-home order's unequal effects on trauma volume by insurance status in Southern California. Surgery. https:// doi.org/10.1016/j.surg.2021.02.060

27. Sanford EL, Zagory J, Blackwell JM, Szmuk P, Ryan M, Ambardekar A (2021) Changes in pediatric trauma during COVID-19 stay-at-home epoch at a tertiary pediatric hospital. J Pediatr Surg 56(5):918-922. https://doi.org/10.1016/j.jpedsurg. 2021.01.020

28. Sheridan GA, Nagle M, Russell S, Varghese S, O'Loughlin PF, Boran S et al (2020) Pediatric trauma and the COVID-19 pandemic: a 12-year comparison in a level-1 trauma center. HSS J 16(Suppl 1):1-5. https://doi.org/10.1007/s11420-020-09807-y

29. Kovler ML, Ziegfeld S, Ryan LM, Goldstein MA, Gardner R, Garcia AV et al (2020) Increased proportion of physical child abuse injuries at a level I pediatric trauma center during the Covid-19 pandemic. Child Abuse Negl 116:104756. https://doi.org/10. 1016/j.chiabu.2020.104756

30. Keays G, Friedman D, Gagnon I (2020) Injuries in the time of COVID-19. Health Promot Chronic Dis Prev Can 40(11-12):336341. https://doi.org/10.24095/hpcdp.40.11/12.02

31. Bram JT, Johnson MA, Magee LC, Mehta NN, Fazal FZ, Baldwin KD et al (2020) Where have all the fractures gone? The epidemiology of pediatric fractures during the COVID-19 pandemic. J Pediatr Orthop 40(8):373-379. https://doi.org/10.1097/BPO. 0000000000001600

32. Hernigou J, Morel X, Callewier A, Bath O, Hernigou P (2020) Staying home during "COVID-19" decreased fractures, but trauma did not quarantine in one hundred and twelve adults and twenty eight children and the "tsunami of recommendations" could not lockdown twelve elective operations. Int Orthop 44(8):1473-1480. https://doi.org/10.1007/s00264-020-04619-5

33. Sidpra J, Abomeli D, Hameed B, Baker J, Mankad K (2021) Rise in the incidence of abusive head trauma during the COVID-19 pandemic. Arch Dis Child 106(3):e14. https://doi.org/10.1136/ archdischild-2020-319872

34. Raitio A, Ahonen M, Jääskelä M, Jalkanen J, Luoto TT, Haara $M$ et al (2021) Reduced number of pediatric orthopedic trauma requiring operative treatment during COVID-19 restrictions: a nationwide cohort study. Scand J Surg 110(2):254-257. https:// doi.org/10.1177/1457496920968014

35. Donnelly M, Grigorian A, Swentek L, Arora J, Kuza CM, Inaba $K$ et al (2021) Firearm violence against children in the United States. J Trauma Acute Care Surg. https://doi.org/10.1097/TA. 0000000000003347. Published online July 1, 2021

36. COVID19.CA.GOV. Latest news on COVID-19. https://covid19. ca.gov/latest-news. Updated May 25, 2021. Accessed May 25, 2021

37. Sutherland M, McKenney M, Elkbuli A (2021) Gun violence during COVID-19 pandemic: paradoxical trends in New York City, Chicago, Los Angeles and Baltimore. Am J Emerg Med 39:225-226. https://doi.org/10.1016/j.ajem.2020.05.006

38. Abdallah HO, Zhao C, Kaufman E, Hatchimonji J, Swendiman RA, Kaplan LJ et al (2021) Increased firearm injury during the COVID-19 pandemic: a hidden urban burden. J Am Coll Surg 232(2):159-168. https://doi.org/10.1016/j.jamcollsurg.2020.09. 028

39. Kim DY, Phillips SW (2021) When COVID-19 and guns meet: a rise in shootings. J Crim Justice 73:101783. https://doi.org/10. 1016/j.jcrimjus.2021.101783

40. Qasim Z, Sjoholm LO, Volgraf J, Sailes S, Nance ML, Perks DH et al (2020) Trauma center activity and surge response during the early phase of the COVID-19 pandemic-the Philadelphia story. J Trauma Acute Care Surg 89(4):821-828. https://doi.org/10.1097/ TA.0000000000002859

41. Gibbs D, Ehwerhemuepha L, Moreno T, Guner Y, Yu P, Schomberg J et al (2020) Prolonged hospital length of stay in pediatric trauma: a model for targeted interventions. Pediatr Res Epub. https://doi.org/10.1038/s41390-020-01237-0

42. Bornstein E, Gulersen M, Husk G, Grunebaum A, Blitz MJ, Rafael TJ et al (2020) Early postpartum discharge during the COVID-19 pandemic. J Perinat Med 48(9):1008-1012. https:// doi.org/10.1515/jpm-2020-0337

43. Greene NH, Kilpatrick SJ, Wong MS, Ozimek JA, Naqvi M (2020) Impact of labor and delivery unit policy modifications on maternal and neonatal outcomes during the coronavirus disease 2019 pandemic. Am J Obstet Gynecol MFM 2(4):100234. https:// doi.org/10.1016/j.ajogmf.2020.100234

Publisher's Note Springer Nature remains neutral with regard to jurisdictional claims in published maps and institutional affiliations.

\title{
Authors and Affiliations
}

\author{
Eric O. Yeates ${ }^{1} \cdot$ Areg Grigorian ${ }^{1,2} \cdot$ Morgan Schellenberg $^{2} \cdot$ Natthida Owattanapanich $^{2} \cdot$ Galinos Barmparas $^{3}$. \\ Daniel Margulies ${ }^{3} \cdot$ Catherine Juillard $^{4} \cdot$ Kent Garber $^{4} \cdot$ Henry Cryer $^{4} \cdot$ Areti Tillou $^{4} \cdot$ Sigrid Burruss $^{5}$. \\ Liz Penaloza-Villalobos ${ }^{5} \cdot$ Ann Lin $^{5} \cdot$ Ryan Arthur Figueras $^{5} \cdot$ Raul Coimbra $^{5,6} \cdot$ Megan Brenner $^{7} \cdot$ Todd Costantini $^{8}$. \\ Jarrett Santorelli ${ }^{8}$. Terry Curry ${ }^{8}$. Diane Wintz ${ }^{9} \cdot$ Walter L. Biff $^{10} \cdot$ Kathryn B. Schaffer $^{10}$ - Thomas K. Duncan $^{11}$. \\ Casey Barbaro ${ }^{11}$. Graal Diaz ${ }^{11}$. Arianne Johnson ${ }^{12}$. Justine Chinn ${ }^{1}$. Ariana Naaseh ${ }^{1}$. Amanda Leung ${ }^{1}$. \\ Christina Grabar ${ }^{1} \cdot$ Jeffry Nahmias ${ }^{1} \mathbb{C}$
}

Eric O. Yeates

yeatese@hs.uci.edu
Areg Grigorian

areg.grigorian@med.usc.edu 
Morgan Schellenberg

morgan.schellenberg@med.usc.edu

Natthida Owattanapanich

natthida.owa@gmail.com

Galinos Barmparas

galinos.barmparas@cshs.org

Daniel Margulies

daniel.margulies@cshs.org

Catherine Juillard

cjuillard@mednet.ucla.edu

Kent Garber

kgarber@mednet.ucla.edu

Henry Cryer

hcryer@mednet.ucla.edu

Areti Tillou

atillou@mednet.ucla.edu

Sigrid Burruss

sburruss@1lu.edu

Liz Penaloza-Villalobos lpenalozavillalobos@1lu.edu

Ann Lin

aclin@1lu.edu

Ryan Arthur Figueras

rfigueras@llu.edu

Raul Coimbra

r.coimbra@ruhealth.org

Megan Brenner

m.brenner@ruhealth.org

Todd Costantini

tcostantini@health.ucsd.edu

Jarrett Santorelli

jsantorelli@health.ucsd.edu

Terry Curry

tcurry@health.ucsd.edu

Diane Wintz

diane.wintzmd@sharp.com

Walter L. Biffl

biffl.walter@scrippshealth.org

Kathryn B. Schaffer

schaffer.kathryn@scrippshealth.org

Thomas K. Duncan

thomas.duncan@ventura.org
Casey Barbaro

casey.barbaro@ventura.org

Graal Diaz

graal.diaz@ventura.org

Arianne Johnson

a11johns@sbch.org

Justine Chinn

jochinn@hs.uci.edu

Ariana Naaseh

anaaseh1@ @hs.uci.edu

Amanda Leung

leungac1@hs.uci.edu

Christina Grabar

grabarc@hs.uci.edu

1 Department of Surgery, University of California, Irvine (UCI), 333 The City Blvd West, Suite 1600, Orange, CA 92868-3298, USA

2 Department of Surgery, University of Southern California (USC), Los Angeles, CA, USA

3 Department of Surgery, Cedars-Sinai Medical Center, Los Angeles, CA, USA

4 Department of Surgery, University of California, Los Angeles (UCLA), Los Angeles, CA, USA

5 Department of Surgery, Loma Linda University, Loma Linda, CA, USA

6 Riverside University Health System Medical Center, Moreno Valley, CA, USA

7 Department of Surgery, University of California, Riverside/Riverside University Health System, Moreno Valley, CA, USA

8 Department of Surgery, University of California, San Diego (UCSD), San Diego, CA, USA

9 Department of Surgery, Sharp Memorial Hospital, San Diego, CA, USA

10 Trauma Department, Scripps Memorial Hospital La Jolla, La Jolla, CA, USA

11 Department of Surgery, Ventura County Medical Center, Ventura, CA, USA

12 Santa Barbara Cottage Hospital, Cottage Health Research Institute, Santa Barbara, CA, USA 